\title{
The nature of constraints on contact-induced change
}

\author{
SHANA POPLACK \\ MARJORY MEECHAN \\ Department of Linguistics, University of Ottawa, Ottawa, \\ ON K1N 6N5, Canada \\ E-mail: spoplack@aix1.uottawa.ca
}

Jeanine Treffers-Daller (henceforth JTD) must be congratulated on what is perhaps the first explicit attempt to verify empirically Thomason and Kaufman (henceforth T\&K)'s (1988) influential claim that the sociolinguistic history of speakers outweighs linguistic structure in determining the linguistic outcome of language contact. Based on quantitative and qualitative comparisons of the effects of contact between French and Dutch in Brussels and Strasbourg, the similarities she detects, despite differences in the sociolinguistic situations, lead her to conclude that the primacy of sociolinguistic history is not supported.

Despite the merits of the paper, there are at least two methodological reasons why its conclusion remains ultimately unconvincing. One involves the difficulties in operationalizing T\&K's model. T\&K had already recognized that in the absence of precise information about how individual social factors conspire to determine the relationship between languages in contact, a clear prediction about the outcome (in terms of what they call "borrowing" and "shift") is impossible to make. Yet the factors pertinent to identifying the "sociolinguistic history" of a speech community are neither made explicit by T\&K, nor operationalized by JTD.

Thus, although a number of differences in the relationship between languages in Brussels and Strasbourg are detailed, it is not clear that these are in fact relevant to their respective sociolinguistic histories. A concrete theory of power differentials in bilingual speech communities would help establish that the situations differ in ways which are demonstrably significant and relevant to the model. Giles's (1979) notion of ethnolinguistic vitality of minority and majority language groups is one such theory. Ethnolinguistic vitality can be evaluated as the sum of several different social factors, including demographics, that is, minority versus majority status; institutional support, that is, official status and educational opportunities; as well as intergroup attitudes, as measured by conflict. All of these factors are cited by JTD.

Once a notion like ethnolinguistic vitality is invoked as a metric, differences between Strasbourg and Brussels with respect to language dominance diminish. Indeed, from this perspective, one could equally well argue for similarities in their sociolinguistic histories. For example, factors detracting from the ethnolinguistic vitality of Dutch in Brussels, such as its minority status, may be offset by institutional support in the schools and media. Conflict with francophone groups could strengthen its role as a contrastive symbol of ethnic identity. Although institutional support and the conflict associated with linguistic expression of ethnic identity are less evident in the case of Alsatian, its vitality is probably maintained by the sheer numbers of its speakers. Moreover, in both cases French is undoubtedly the more powerful language, whether measured in terms of overall number of speakers, differences in official status or recognition worldwide. Thus, evaluation of differences between communities depends on the characterization of sociolinguistic history. A sine qua non for determining the relative contribution of social versus structural factors to contact-induced change would seem to be a clarification of the social factors involved and their significance.

JTD's claim for the primacy of linguistic factors is further challenged by findings consistent with T\&K's claim showing that the typological characteristics of the contact languages are not major predictors of the outcome in other speech communities. An early comparison of a French-English bilingual community in Ottawa with a Spanish-English community in New York showed clear differences in the types of language mixture, despite the typological similarities in the contact languages (Poplack, 1985/1988). Studies of contact between Arabic and French (e.g. Na'it M'Barek \& Sankoff, 1988; Sankoff \& Na'it M'Barek, 1990) have confirmed that patterns of combining the same two languages may differ dramatically from community to community, a result that can only be attributed to factors of an extralinguistic nature. Perhaps the strongest evidence of the role of sociolinguistic history comes from Adalar and Tagliamonte's (1998) study of Turkish-English bilingualism, involving both the same speech community and the same language pair. Even here, patterns of language mixture vary according to speaker generation and sociolinguistic situation, showing that differences in bilingual behavior can be directly linked to differences in the social situation of 
speakers. A claim for the primacy of linguistic factors in contact-induced change should account for these other results.

Even admitting that JTD's characterizations of the sociolinguistic differences between Brussels and Strasbourg are both pertinent and correct, there remains another reason why this study is not an empirical test of T\&K's theory. T\&K presented a framework for contact-induced language change; JTD's invocation of synchronic linguistic evidence only (e.g. nonce borrowing, codeswitching and interference) is of uncertain relevance. While the lexical and structural outcomes she cites are undoubtedly the result of language contact, we do not know which, if any, result from change, contact-induced or otherwise. For example, included in counts of borrowed items are both attested loanwords and other-language items which are ambiguous as to borrowing or codeswitch status. JTD does not distinguish among them, since this does not affect the distinction she wants to test (between lexical and structural outcomes). However, these phenomena are differentially related to change. Attested loanwords may be argued to have altered the lexicon, but no evidence is provided, in apparent or real time, that the ambiguous lexical items (whether considered nonce borrowings or codeswitches) have changed the languages in which they are temporarily incorporated.

Thus, despite its important contributions on the synchronic comparative level, this study falls short as an empirical test of T\&K's model, and by extension, as a predictor of the effects of specific types of language contact. The sociolinguistic history of a contact situation cannot be characterized by listing the appropriate social factors, no matter how exhaustively, but rather requires a more complex analysis of the social situation and possible interaction between competing factors. Before we can assess the effect of sociolinguistic history on contact-induced change, we require a more precise definition of the notion of sociolinguistic history and a method for calculating its value, as well as knowledge of whether the linguistic phenomena adduced as evidence in fact result from change. Studies such as this one are a valuable first step.

References

Adalar, N., \& Tagliamonte, S. (1998). Borrowed nouns; Bilingual people: The case of the "Londralo" in North Cyprus. Instant

Loans, Easy Conditions: The Productivity of Bilingual Borrowing.

Special Issue, International Journal of Bilingualism, 2

(2), 139-159.

Giles, H. (1979). Ethnicity markers in speech. In K.R. Scherer \&

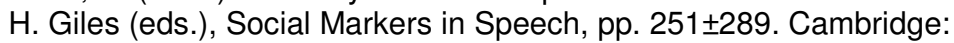

Cambridge University Press.

Na'it M'Barek, M. \& Sankoff, D. (1988). Le discours mixte arabe/

francais: des emprunts ou des alternances de langue? Revue

Canadienne de Linguistique. 33 (2): 143-154.

Poplack, S. (1985/1988). Contrasting patterns of code-switching in

two communities. In M. Heller (ed.), Code-switching: Anthropological

and sociolinguistic perspectives, pp. 215-244. TheHague: Mouton.

Sankoff, D., \& Na'it M'Barek, M. (1990). Dramatically constrasting

language mixture strategies in two communities of fluent Arabic-French bilinguals. Paper

presented at NWAVE 19. University of Pennsylvania.

Thomason, S. G., \& Kaufman, T. (1988). Language contact, creolization and genetic linguistics. Berkeley and Los Angeles, CA: University of California Press. 